\title{
Associative learning in a network model of Hermissenda crassicornis
}

\section{Experiments}

\section{Susan A. Werness ', S. Dale Fay ', Kim T. Blackwell ${ }^{2}$, Thomas P. Vogl ${ }^{2}$, Daniel L. Alkon ${ }^{3}$}

${ }^{1}$ Environmental Research Institute of Michigan, P.O. Box 134001, Ann Arbor, MI 48113-4001, USA

2 Environmental Research Institute of Michigan, 1101 Wilson Blvd., Suite 1100, Arlington, VA 22209, USA

3 Laboratory of Adaptive Sciences, National Institute of Neurological Disorders and Stroke, National Institute of Health, Bethesda, MD 20892, USA

Biol. Cybern. 69, 19-28 (1993)

The error bars on Figs. 3, 4, 5 and 7 are incorrect and should be ignored. The variance (and standard errors) of the ratio of the pre-training mean to the post-training mean cannot be computed correctly, because the covariance between the pre- and post-training groups is not available from the published data on Hermissenda. 